\title{
Realia con escritura: motivación y reflexión metalingüística sobre la L1 en la formación del profesorado
}

\author{
Juana-Rosa Suárez Robaina \\ Universidad de Las Palmas de Gran Canaria, Las Palmas, España
}

\begin{abstract}
Resumen
Esta investigación explora el potencial pedagógico y motivacional de los realia con escritura, objetos de la vida real que incorporan muestras lingüísticas. Su propósito general es indagar la efectividad de su aplicación en la materia de Lengua Castellana y Literatura. A partir de ello, se motiva el diseño de dinámicas y actividades para propiciar no solo el prescriptivo proceso metalingüístico sobre la lengua materna, sino el diseño creativo de dinámicas para el aula. Suma la ventaja de aprender, desde un enfoque significativo y experiencial, con objetos cotidianos que integran muestras escritas de la lengua materna. Se convierte en una ocasión estratégica para abordar especialmente aspectos transversales y epistemológcios del idioma. Sigue los principios de la practicidad del proceso de enseñanza-aprendizaje y del enfoque del aprender haciendo. Su ámbito de aplicación es un posgrado universitario de formación del Profesorado, y los resultados obtenidos en un universo de 29 estudiantes graduados evidencian la oportunidad didáctica de esta metodología.
\end{abstract}

\section{Palabras clave}

Realia con escritura. Motivación docente. Formación del profesorado. Reflexión metalingüística.

\section{Realia com a escrita: motivação e reflexão metalinguística em L1 na formação de professores}

\begin{abstract}
Resumo
Esta pesquisa explora o potencial pedagógico e motivacional dos realia com a escrita, objetos da vida real que incorporam amostras linguísticas. Seu objetivo geral é investigar a eficácia de sua aplicação em matéria de Língua e Literatura Espanhola. A partir disso, o desenho de dinâmicas e atividades é motivado a promover não só o processo metalinguístico prescritivo na língua materna, mas também o desenho criativo de dinâmicas para a sala de aula. Acrescenta a vantagem de aprender, a partir de uma abordagem significativa e experiencial, com objetos do cotidiano que integram amostras escritas da língua materna. Torna-se uma ocasião estratégica para abordar aspectos especialmente transversais e epistemológicos da linguagem. Segue os princípios da praticidade do processo de ensino-aprendizagem e da abordagem do aprender fazendo. Seu escopo de aplicação é uma pós-graduação universitária em formação de professores, e os resultados obtidos em um universo de 29 alunos de pós-graduação mostram a oportunidade didática dessa metodologia.
\end{abstract}

\section{Palavras-chave}

Realia com a escrita. Motivação docente. Treinamento docente. Reflexão metalinguística. 


\title{
Realia with writing: motivation and metalinguistic reflection
}

\section{on L1 in teacher training}

\begin{abstract}
This research explores the pedagogical and motivational potential of realia with writing, real-life objects that incorporate linguistic samples. Its general purpose is to investigate the effectiveness of its application in the matter of Spanish Language and Literature. From this, the design of dynamics and activities is motivated to promote not only the prescriptive metalinguistic process on the mother tongue, but also the creative design of dynamics for the classroom. It adds the advantage of learning, from a meaningful and experiential approach, with everyday objects that integrate written samples of the mother tongue. It becomes a strategic occasion to deal especially with transversal and epistemological aspects of the language. It follows the principles of the practicality of the teaching-learning process and the learning-by-doing approach. Its scope of application is a university postgraduate degree in teacher training, and the results obtained in a universe of 29 graduate students show the didactic opportunity of this methodology.
\end{abstract}

\section{Keywords}

Realia with writing. Teaching motivation. Teacher training. Metalinguistic reflection.

\section{Introducción}

El concepto realia (objetos reales), en buena parte de la literatura científica de las últimas tres décadas (ÁLVAREZ, 2011; BERWARLD, 1987; CANCELAS, 1998; CARRASCO, 2016; CAZORLA, 2013; FERNÁNDEZ, 2000; GEBHARD, 1996; GELABERT et al., 2002; HERNÁNDEZ, 2017; MOCHÓN, 2005; RICHARDS; PLATT, J.; PLATT, H., 1992), se ha caracterizado por mostrar cierta flexibilidad en la interpretación misma de lo que implica: en su generalidad, el uso de materiales "reales" como soporte pedagógico para la mejora del aprendizaje de lenguas. Se caracterizan por ser objetos o materiales naturales, carentes por tanto de cualquier intervención o manipulación del docente. Esto los aproxima a su etiqueta extendida de materiales auténticos, que el aprendiz es capaz de identificar y reconocer en un contexto natural o extraacadémico, pero que indudablemente no han nacido con una intención didáctica o formativa a priori. Precisando aún más y según una ya pretérita aclaración de Berwarld (1987), los materiales auténticos se caracterizan especialmente por proporcionar una información o input cultural que va a ser sin duda relevante para el aprendizaje de una lengua (folletos, revistas, mapas de trenes...) 
frente al realia propiamente dicho, que no aporta información lingüística alguna (monedas, muñecos, frutas de plástico, fotografías...), pero que se usan como importante elemento motivador y estimulador de la interacción lingüística, como ejemplos y apoyos visuales (GEBHARD, 1996).

La metodología realia acumula tradición de uso en la enseñanza-aprendizaje de segundas lenguas, pues se ambienta en el enfoque comunicativo y las subsecuentes interacciones orales, propiciadas por las reacciones ante los objetos "inspiradores" empleados. Se trata por tanto de una metodología que fomenta la visión instrumental de la lengua meta al usarla de forma "real", a través de la comunicación oral contínua y constante que genera las discusiones e interacciones en torno a los objetos.

La investigación que presentamos, enmarcada en una experiencia universitaria de un Posgrado profesionalizador ${ }^{1}$, explora, sin embargo, una variante (Tabla 1) y es el potencial didáctico de lo que hemos denominado realia con escritura. Nos referimos así a objetos de la vida real, de naturaleza "doméstica" y que incorporan, además, texto, es decir, muestras de lengua viva. En esta investigación, hemos excluido por ello tanto a los realia propiamente dichos como a los materiales auténticos (antes aludidos); hemos puesto el foco en el uso de objetos cercanos al estudiante, que incluyen muestras de lengua en uso, con los que el aprendiz (en este caso, futuro profesor) puede establecer una conexión personal, más natural y espontánea. El principio pedagógico que además alienta esta propuesta es el fin último que la anima: ser un proyecto didáctico para enseñar a futuros docentes cómo estimular la reflexión sobre la propia lengua materna desde el empleo de muestras de lengua insertadas en la realidad cercana del estudiante, a través de un banco motivador y específico de objetos. Se refuerzan así al unísono las distintas dimensiones (o subcompetencias) que integran la competencia comunicativa (MCERL, 2002) desde la lingüística (en sus niveles fonológico, léxico-semántico, gramatical, etc.), hasta la sociolingüística (cortesía, registros...) y la pragmática (discursiva, funcional, organizativa...).

1 Desarrollada en la asignatura Aprendizaje y enseñanza en la especialidad de Lengua cast. y Literatura, en el Posgrado Máster Univ. en Formación del Profesorado de Educación Secundaria Obligatoria y Bachillerato, Formación Profesional y Enseñanza de Idiomas por la ULL y la ULPGC.

Educ. Form., Fortaleza, v. 6, n. 1, e3613, jan./abr. 2021

DOI: https://doi.org/10.25053/redufor.v6i1.3613

https://revistas.uece.br/index.php/redufor/index ISSN: 2448-3583 
Tabla 1 - Tipología de materiales

\begin{tabular}{|c|c|c|c|}
\hline & No & No & Sí \\
\hline $\begin{array}{c}\text { Objetos de } \\
\text { investigación } \\
\text { empleados en } \\
\text { nuestro Proyecto }\end{array}$ & $\begin{array}{c}\text { Realia u objetos reales } \\
\text { (sin escritura añadida) } \\
\Downarrow \\
\text { muñecos, monedas, } \\
\text { frutas de plástico... }\end{array}$ & $\begin{array}{c}\text { Materiales auténticos (con } \\
\text { información de fuerte } \\
\text { input cultural) } \\
\Downarrow \\
\text { mapas, catálogos, } \\
\text { folletos de viajes... }\end{array}$ & $\begin{array}{c}\text { Realia con escritura } \\
\text { ("cosas" con muestras de } \\
\text { lengua en uso } \\
\downarrow \\
\text { servilletas, vasos de } \\
\text { yogur, bolsas, etiquetas, } \\
\text { cajas de zapatos... }\end{array}$ \\
\hline
\end{tabular}

Fuente: Elaboración propia (2020).

Nuestra investigación persigue por ello evidenciar la fortaleza pedagógica de los objetos cotidianos, domésticos, que contengan escritura y que permitan así una aproximación, desde la perspectiva conjunta motivacional (1) y metalingüística (2), a una reflexión fundamentada en la especialidad docente de Lengua Castellana y Literatura.

La incidencia de la motivación en el aprendizaje (1) permea de modo natural nuestro proyecto. En el caso de los estudiantes objeto de esta investigación, hay que aclarar que se trata, a su vez, de futuro profesorado, por lo que ya se le atribuye a priori una motivación intrínseca, por querer aprender más para querer enseñar mejor. Identificamos así en ellos una motivación intrínseca fundamentada en factores internos (autodeterminación, curiosidad, desafío, esfuerzo) y les presuponemos un deseo y un gusto personal (derivado de su estatus académico como inminentes profesores) por indagar en nuevas metodologías. Coincidimos con Ryan y Deci (2000) en que partir de una elevada motivación intrínseca es, sin duda alguna, partir de un contexto de aprendizaje ideal.

Frente a esto, es preciso impulsar la motivación extrínseca, es decir, que nuestro modo (como docentes e instructores) de proveer de nuevos conocimientos, recursos y estrategias didácticas esté a la altura de sus expectativas, les anime a progresar académicamente hablando (recompensa), les involucre en el proceso de enseñanza-aprendizaje (aprendizaje significativo) y les sirva asimimo de modelo inspirador (por su carácter innovador) en su futura tarea docente.

La dimensión metalingüística (2), por su parte, se vincula con el ejercicio de indagación y de introspeccción que el estudiante puede hacer sobre su propia lengua y especialmente se manifiesta cuando activa o muestra su capacidad para verbalizarla (PERALES, 2004). Habitualmente las acciones metalingüísticas se evidencian cuando pedimos aclaraciones y reformulamos nuestro discurso (sobre todo en el habla coloquial), cuando revisamos o cuando autocorregimos nuestras propias intervenciones, pero están 
especialmente presentes "[...] en todo proceso de aprendizaje de lenguas; porque uno de los modos en que aprendemos consiste en hablar de cómo se habla, reflexionar sobre la lengua, darles nombre a formas y funciones [...]" (PASTOR, 2004, p. 639).

Para desarrollar la metodología realia con escritura, los objetos elegidos deben cuidar, obviamente, ambas dimensiones (la motivacional y la metalingüística). A partir de esas premisas, la selección de materiales atiende a dos criterios fundamentales: en primer lugar, la elección de un banco de útiles (Tabla 2) que responda a las características de un objeto visual, "tridimensional y tangible" (ÁLVAREZ, 2011, p. 14), identificable y reconocible, a ser posible, en el contexto natural, personal y social del estudiante o aprendiz. Hablamos incluso de cierta identidad afectiva y pragmática del objeto y, cómo no, de su coste prácticamente cero y hallazgo inmediato. Es requisito sine qua non contener muestras significativas de la lengua viva; en atención al nivel de los destinatarios, se pueden incluir también útiles con muestras idiomáticas de una segunda lengua. Esto último se garantiza dada la tipología textual (fundamentalmente publicitaria y literaria) contenida en los objetos escogidos.

Tabla 2 - Muestra de realia con escritura repartidos a los estudiantes

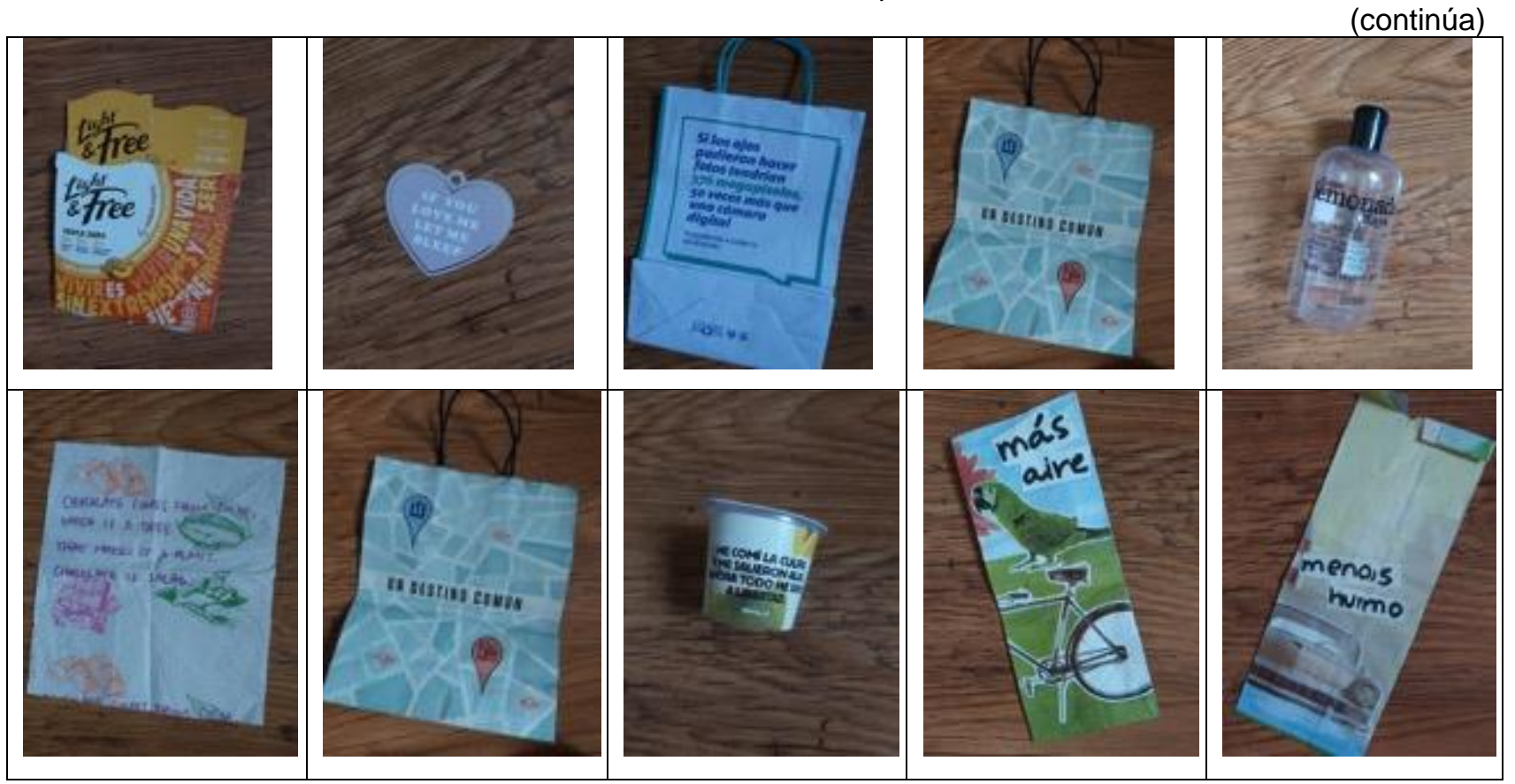

Educ. Form., Fortaleza, v. 6, n. 1, e3613, jan./abr. 2021

DOI: https://doi.org/10.25053/redufor.v6i1.3613

https://revistas.uece.br/index.php/redufor/index 
Tabla 2 - Muestra de realia con escritura repartidos a los estudiantes
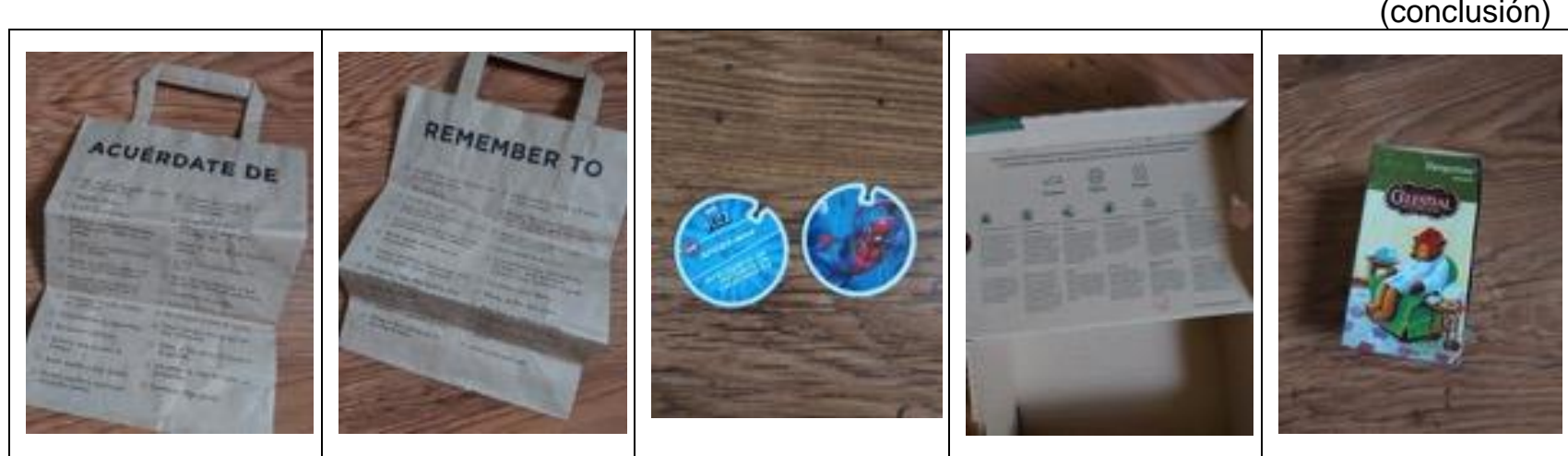

Fuente: Elaboración propia (2020).

El segundo criterio que organiza la selección es la previsión de que el estudiante pueda advertir (Tabla 3), en los mensajes incorporados en los objetos, la identificación de "posibles" contenidos de la especialidad de Lengua Castellana y Literatura.

Tabla 3 - Taxonomía de contenidos susceptibles de reconocer

Contenidos de naturaleza epistemológico-conceptual, vinculados a los diferentes componentes del sistema de un idioma: componente fonético-fonológico, léxico-semántico, morfosintáctico.

Contenidos de naturaleza nociofuncional o instrumental: los denominados "saberes" (saber inferir, saber jerarquizar o hacer un esquema, saber desarrollar un eje cronológico, saber definir, saber redactar, saber expresar una opinión, saber reconocer las distintas tipologías textuales...).

Contenidos de naturaleza sociocultural, artística, estética. Aquí incluimos tanto los textos aprovechables para la perspectiva transversal de la materia (valores o ejes transversales) como los contenidos estilísticos y literarios, los referentes estético-culturales, las normas, pautas y rutinas, etc.

Fuente: Elaboración propia (2020).

Como actividad o dinámica de demostración (MERRILL, 2002), se comentan en el aula algunos ejemplos (Tabla 4).

Tabla 4 - Ejemplo de diagnóstico de contenidos

\begin{tabular}{|c|c|c|c|}
\hline \multirow[t]{2}{*}{$\begin{array}{c}\text { Realia con escritura } \\
\text { (bolsa de Correos) }\end{array}$} & \multicolumn{3}{|c|}{ Contenidos } \\
\hline & Epistemológicos o conceptuales & $\begin{array}{c}\text { Nociofuncionales/ } \\
\text { Instrumentales }\end{array}$ & $\begin{array}{l}\text { Socioculturales, } \\
\text { artísticos, estéticos }\end{array}$ \\
\hline $\begin{array}{l}\text { DOH CORREOS } \\
\text { COMPARTR LO MEOR } \\
\text { DE TUS VACACIONES } \\
\text { ESTA EN TUS MANOS }\end{array}$ & $\begin{array}{l}\text { - Uso de la doble rr en español } \\
\text { - Hiato (correos) y diptongo } \\
\text { (vacaciones) } \\
\text { - Tilde en palabras agudas } \\
\text { - Los sustantivos } \\
\text { pluralia tantum (vacaciones) } \\
\text { - Préstamos del español } \\
\text { (correos, portuguesismo) } \\
\text { - Grados del adjetivo } \\
\text { - El adjetivo posesivo } \\
\text { - Preposiciones en español } \\
\text { - Los verbos compuestos } \\
\text { - Or. subordinadas sustantivas de } \\
\text { sujeto (“Ello" está en tus manos) }\end{array}$ & $\begin{array}{c}\text { - Saber escribir una } \\
\text { postal } \\
\text { (Práctica con } \\
\text { tipologías textuales) }\end{array}$ & $\begin{array}{l}\text { - Identificación de } \\
\text { la dilogía } \\
\text { está en tus manos } \\
\text { (a) depende de ti } \\
\text { (b) la postal la } \\
\text { escribes a mano } \\
\text { - Estilo y tono de un } \\
\text { eslogan publicitario } \\
\text { - Guiño a los } \\
\text { colores de la } \\
\text { bandera española } \\
\text { en la bolsa de } \\
\text { Correos } \\
\text { (empresa estatal } \\
\text { española) }\end{array}$ \\
\hline
\end{tabular}

Fuente: Elaboración propia (2020).

Educ. Form., Fortaleza, v. 6, n. 1, e3613, jan./abr. 2021

DOI: https://doi.org/10.25053/redufor.v6i1.3613

https://revistas.uece.br/index.php/redufor/index 
El uso de los materiales realia con escritura en tanto que actualización de los recursos didácticos con los que se trabaja se alinea con el discurso curricular (RD 83/2016), que insiste en la importancia de una práctica comunicativa más reflexiva y contextualizada. Concretamente en el currículo del área de Lengua Castellana y Literatura (en adelante, LCyL), se nos recuerda que:

[...] aprender lengua significa avanzar en el conocimiento implícito y explícito que un hablante posee sobre su propio idioma, durante el proceso de su desempeño comunicativo, cuando habla, conversa, escucha, lee o escribe, en un contexto de uso social o cultural determinado. (DECRETO, 2016, p. 878).

Y promueve la necesaria reflexión sobre una acción docente cómplice y promotora de una enseñanza más eficaz (MURILLO; MARTíNEZ-GARRIDO; HERNÁNDEZ-CASTILLA, 2011) desde el momento que tiende al uso de recursos, en este caso alternativos, con los que el aprendiz puede establecer un diálogo formativo diferente y motivador, que excede el mero aprendizaje teórico. Están presentes los principios de la practicidad del proceso de enseñanza-aprendizaje (DEWEY, 2007) y los del enfoque del Learning by doing (SCHANK, 2005), que dan respuesta asimismo a una de las competencias específicas del posgrado en el que se contextualiza esta investigación: "Favorecer la comunicación verbal en el aula y valorar las aportaciones de los estudiantes". La conexión se estrecha, además, si se tiene en cuenta la propia naturaleza, mayoritariamente publicitaria y en ocasiones literaria, de los mensajes contenidos en estos objetos, y particularmente en los que hemos seleccionado. Se advierte por tanto su beneficio pedagógico en tanto que materiales que establecen una fuerte relación con el medio social de los aprendientes, como decíamos anteriormente, a propósito de su naturaleza visual y pragmática. Los realia con escritura se sumarían así al potencial de objetos o artefactos susceptibles de trabajarse desde la perspectiva de la semiótica multimodal (JEWITT, 2008; KRESS; VAN LEEUWEN, 1996; LÓPEZ, 2020) al ser soportes comunicativos que despliegan múltiples posibilidades para significar y aprender con ellos (KRESS, 2010).

La propuesta también desarrolla la creación, en su fase final, de actividades de aula orientadas al alumnado de la etapa educativa de Secundaria. Se completa, de este modo, el entrenamiento del futuro profesor en las acciones que habrá de desempeñar en su próxima práctica profesional y se alinea por tanto este proceder con la necesidad de 
revitalizar el espacio de formación de los futuros docentes, fortaleciendo, por una parte, la actitud reflexiva sobre los propios conocimientos (LIMA; ANDRADE; COSTA, 2020), y, por otra, alentando la permanente revisión de la formación continua de los profesores (JUNGES; KETZER; OLIVEIRA, 2018).

\section{Metodología}

Esta investigación se llevó a cabo en el marco docente de un posgrado universitario, concretamente en la materia Aprendizaje y Enseñanza de la especialidad de Lengua Castellana y Literatura, perteneciente al Máster Universitario en Formación del Profesorado de Educación Secundaria Obligatoria y Bachillerato, Formación Profesional y Enseñanza de Idiomas por la Universidade de La Laguna y la Universidade de Las Palmas de Gran Canarias (en adelante, MUFP).

Parte inicialmente de un enfoque cualitativo de investigación, desde una perspectiva interaccionista (BAELO; HAZ, 2019), motivada por la relación docente con el grupo participante. Se ha desarrollado con distintas técnicas y herramientas o instrumentos cualitativos de recopilación de información; la adición de la técnica cuantitativa del sondeo, a través de un cuestionario semiestructurado, para determinar la percepción de la experiencia por parte de los participantes, la convierte en una investigación mixta. Para el seguimiento y desempeño, evaluación y coevaluación del resultado final, se generó una rúbrica (escrita) de diseño propio y, para dar respuesta a la técnica de la auto-observación, se acudió a la reflexión grupal oral.

\subsection{Objetivos}

Plantea, como corresponde a una investigación aplicada interesada en la mejora educativa, un objetivo principal o general y unos derivados que contribuyen a perfilarla. El objetivo general (O1) ha sido desarrollar una reflexión fundamentada y, al mismo tiempo, una reivindicación de la fortaleza pedagógica de los realia con escritura en el ámbito académico. A partir de este objetivo, hemos desglosado un total de siete subobjetivos o metas:

(O2) Instruir en la necesidad del aprendizaje "práctico" de una lengua.

Educ. Form., Fortaleza, v. 6, n. 1, e3613, jan./abr. 2021

DOI: https://doi.org/10.25053/redufor.v6i1.3613

https://revistas.uece.br/index.php/redufor/index 
(O3) Diseñar un Proyecto de investigación aplicado a un grupo de profesores en formación.

(O4) Identificar contenidos de la especialidad de LCyL en el conjunto de objetos (realia con escritura) entregado a cada subgrupo cooperativo participante y crear actividades para Secundaria con dichos objetos.

(O5) Diagnosticar el proceso experiencial de los participantes con el uso de los realia con escritura, su satisfacción y prospectiva, mediante un cuestionario específico o ad hoc.

(O6) Evaluar la creatividad y versatilidad del empleo de este recurso en el aula a través del repertorio de propuestas didácticas diseñado por cada subgrupo participante.

(O7) Comprobar mediante la coevaluación las destrezas comunicativa, persuasiva... de los participantes en el refrendo o no del empleo de los realia con escritura para el aula.

\subsection{Participantes}

La investigación se ha llevado a cabo con la totalidad del grupo de masterandos de la especialidad de LCyL. Se trata de un total de 29 estudiantes graduados - por lo que los consideramos profesores en formación -, 23 mujeres y seis hombres, con asistencia regular a las sesiones presenciales del MUFP durante el curso académico 2019-2020. La docencia se ha implementado con un recurso educativo complementario: el edublog Aprendizaje y Enseñanza².

\subsection{Técnicas de investigación e instrumentos}

Metodológicamente hablando, partimos del enfoque del aprendizaje significativo y orientado a la acción que busca atender tanto la variable motivacional (aprender a partir de lo que ya sabemos, involucrarnos, interés, autoeficacia y meta competencial) como la propia reflexión metalingüística sobre la lengua materna (L1), circunstancia básica en la inmediata praxis de estos masterandos.

2 Disponible en: http://solotuaprendizaje.blogspot.com.

Educ. Form., Fortaleza, v. 6, n. 1, e3613, jan./abr. 2021

DOI: https://doi.org/10.25053/redufor.v6i1.3613

https://revistas.uece.br/index.php/redufor/index 
Se han empleado diferentes técnicas de investigación con sus respectivos instrumentos (Tabla 4) durante el transcurso del Proyecto. Se activó, en primer lugar, el debate a partir de la técnica del grupo de discusión o grupo focal (01, O2 y O3). La versatilidad de la técnica metodológica de los grupos focales (BAELO; HAZ, 2019) permite su uso en distintos momentos de la investigación, y así fue en nuestro caso. Como elemento previo al debate, se ejemplificó (y partiendo también de las propias experiencias y conocimientos de los estudiantes) con un diagnóstico improvisado de contenidos extraídos de algunos objetos, desarrollándose así consecutivamente lo que Merrill (2002) identifica como dinámicas o actividades de activación y de demostración. Tras esta "muestra", se distribuyó la pauta-protocolo (Anexo 1) del Proyecto y se activó el debate propiamente dicho en el grupo focal.

La segunda técnica empleada ha sido la observación directa o participante (O1, O2 y O3) en nuestra calidad de docente-mediadora participante con escucha activa. Los elementos que han propiciado esta técnica cualitativa de investigación han sido: un contexto grupal regular (sesiones prácticas en el aula de Informática), oportunidades de asistir a las reflexiones (formales y no formales) desarrolladas en esas sesiones prácticas y un sistema básico de registro o instrumento consistente en las aportaciones de los estudiantes a una serie de entradas específicas del blog, algunas con aspectos tangenciales al tópico de la investigación ${ }^{3}$ (concretamente las entradas números 138 , 143, 145 y 151). En este punto de la investigación, sin duda alguna, las interacciones espontáneas (sobre todo orales), generadas a raíz de las reflexiones propuestas en las entradas señaladas, nos han permitido contar con datos valiosos sobre el tópico de nuestra investigación (aceptación/rechazo, idoneidad para el aula, hallazgos...), que, de otro modo, no hubiera sido posible registrar, al menos, con tanta certidumbre de autenticidad. Siguiendo a Merrill (2002), las actividades que aquí se generan corresponden a la aplicación y a la demostración.

Por otra parte, y para recoger las percepciones del proceso experiencial con el uso de los realia con escritura (su satisfacción y prospectiva) correspondiente al objetivo 5, se empleó la técnica del sondeo (técnica cuantitativa) a través del instrumento del cuestionario.

${ }^{3}$ Resultaron especialmente interesantes las opiniones verbales referidas a la oportunidad de los realia con escritura para trabajar tipologías textuales alternativas. Se redunda así en la practicidad de la lengua y concretamente en el concepto de lengua en uso opuesto al de lengua como sistema.

Educ. Form., Fortaleza, v. 6, n. 1, e3613, jan./abr. 2021

DOI: https://doi.org/10.25053/redufor.v6i1.3613

https://revistas.uece.br/index.php/redufor/index 
Se diseñó un cuestionario específico (ad hoc) online mediante un software libre (Google Forms). El cuestionario se revela como un instrumento útil para recoger información de manera sistemática y ordenada. Su necesidad en los procesos de investigación ya la demandan, entre otros, Martín (2004), Alvira (2011) e Icart y Pulpón (2012). Para nuestro estudio de corte descriptivo, se elaboró un cuestionario semiestructurado con enunciados muy concretos que pretendían evidenciar las percepciones de los estudiantes al usar los realia con escritura. Contó con un bloque I o previo de preguntas de perfil demográfico y un bloque II o específico. En este último, se distribuyó un total de ocho ítems: del 01 al 05, con preguntas cerradas con cuatro opciones o categorías de respuesta breve (Poco/Regular/Bastante/Mucho); el ítem 06 con cinco opciones excluyentes, aunque más elaboradas en su formulación; el ítem 07 , que daba opción a una respuesta abierta; y finalmente el ítem 08, de pregunta mixta (ofrece opciones guiadas y la posibilidad de añadir otras personales). El cuestionario implica una actividad de aplicación (MERRILL, 2002).

Finalmente, para verificar el seguimiento y marcha (evaluación y coevaluación), comprobar la capacidad de identificar contenidos de la especialidad en los objetos recibidos por cada subgrupo, diseñar actividades a partir de ese diagnóstico y exponer al gran grupo el proyecto realizado (04, 06 y O7), se utilizó, por un lado, la técnica de seguimiento/desempeño materizalizada en una rúbrica (escrita) de diseño propio (Anexo 2) y, por otro, la técnica de la auto-observación (oral), manifestada en la reflexión grupal presencial (IGLESIAS; GALICIA, 2018), que también tuvo lugar en la última sesión docente.

Las acciones vinculadas a estos objetivos se traducen, siguiendo a Merrill (2002), en actividades de aplicación e integración.

Tabla 5 - Relación de las técnicas con sus instrumentos y los objetivos de la investigación
Técnica del Grupo de discusión o focal
Debate
$\mathrm{O} 1, \mathrm{O} 2, \mathrm{O} 3$
T. de la Observación directa o participante
Anotaciones/Cuaderno de campo/Entradas Blog
T. del Sondeo Cuestionario (software libre
$\mathrm{O} 1, \mathrm{O} 2, \mathrm{O} 3$ Google Forms)
O5
T. de Seguimiento/desempeño Rúbrica (escrita)
O4, O6, 07
T. de la Auto-observación

\section{Fuente: Elaboración propia (2020).}




\section{Resultados}

Conviene, para delimitar los resultados, expresar las fases seguidas en la investigación. Parafraseamos para ello a Vallés (1999), que distingue lo siguiente:

Fase 1 o de reflexión, donde se procede a identificar el problema de investigación y su estado de la cuestión. Se corresponde en nuestro caso con la concreción de los tópicos: el posible aprovechamiento didáctico de materiales realia con escritura por entender que beneficia la dimensión emocional de los aprendientes y el refuerzo de la reflexión metacognitiva sobre su propia lengua materna. Se interactúa con el grupo focal o de discusión. Se vincula con $\mathrm{O} 1$ y $\mathrm{O} 2$.

Fase 2 o de planeamiento, en la que tiene lugar el diseño del proceso que se va a seguir, con la concreción por nuestra parte del Proyecto de investigación (La lengua de las cosas: leer los objetos. Uso de realia con escritura), que se presenta y discute ante el grupo focal (Anexo 1). Vinculada con $\mathrm{O} 3$.

Fase 3 o de entrada, en la que ya se delimitan los destinatarios del proceso de investigación. Se concretan en el grupo focal los seis subgrupos de trabajo, se ilustra con muestras o ejemplos del proceder y se procede al "reparto" de los objetos". Los subgrupos participantes proceden a partir de ese momento a trabajar cooperativamente su "compra" de realia con escritura. Vinculada con O2 y O3.

Fase 4 o de recogida de datos y análisis preliminar, en la que se inicia el análisis a partir de los instrumentos de recogida creados para la investigación. Concretamente aquí se analiza el resultado del sondeo materializado en el cuestionario ad hoc. Vinculada a $\mathrm{O} 4$ y $\mathrm{O} 5$.

Fase 5 o de salida del campo y análisis, en la que se ultiman todos los datos. Coincide con la puesta en escena de los diseños de los subgrupos que muestran así el resultado de la experiencia presentando sus diseños (véase una muestra en el Anexo 3) y resolviendo tanto la rúbrica (ejercicio escrito de coevaluación, Anexo 2) como la auto-observación (oral). Vinculada con $\mathrm{O} 6$ y $\mathrm{O} 7$.

Fase 6 o de redacción del informe o artículo.

4 En esa performance didáctica se llevó al aula un carrito de biblioteca (parecido al de los supermercados) con los diferentes "paquetes". Se preparó un total de seis. La variante que obviamente se discute con los estudiantes es que sean ellos mismos los que hagan acopio de los objetos. Optamos por facilitarlos nosotros (ganar tiempo, motivación extrínseca...).

Educ. Form., Fortaleza, v. 6, n. 1, e3613, jan./abr. 2021

DOI: https://doi.org/10.25053/redufor.v6i1.3613

https://revistas.uece.br/index.php/redufor/index 
Por cuestiones de espacio, nos centramos a continuación en presentar los resultados de la herramienta cuantitativa empleada (Fase 4, O4 y O5), es decir, del cuestionario específico diseñado al efecto y que da cuenta de las percepciones de los estudiantes de su proceso experiencial.

De su Bloque I (datos demográficos) nos pareció interesante indagar por la formación complementaria de los estudiantes (a nivel de otro Posgrado):

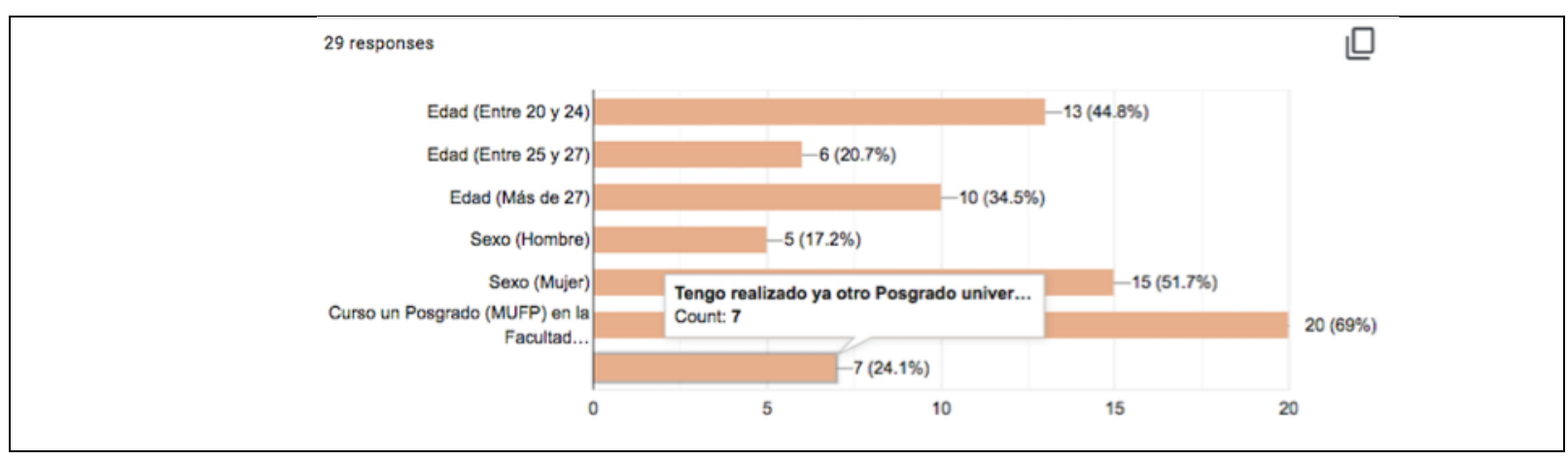

Los ítems del 01 al 05 muestran preguntas cerradas con cuatro opciones 0 categorías de respuesta breve (Poco/Regular/Bastante/Mucho), todas consideradas válidas (100\%).

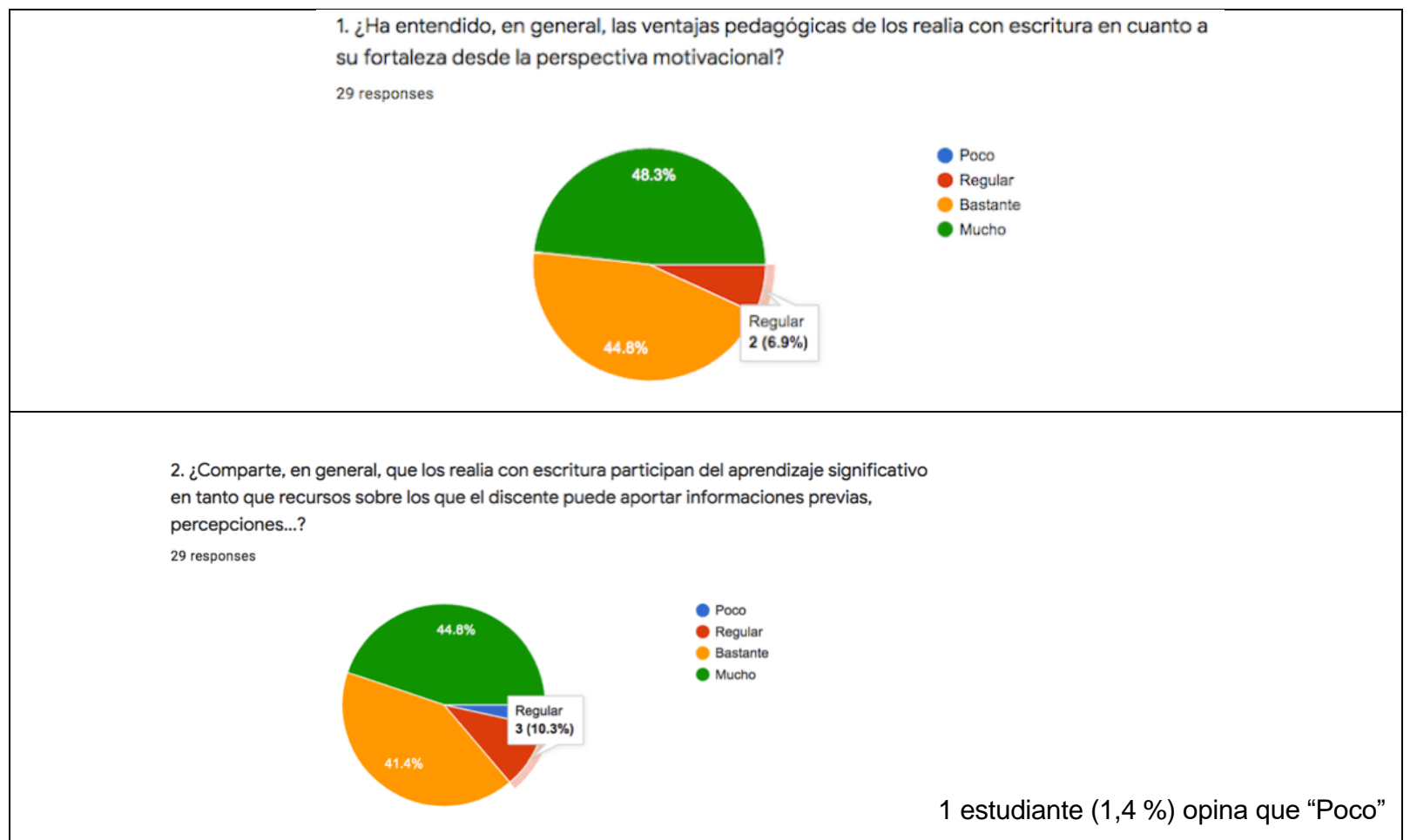

Educ. Form., Fortaleza, v. 6, n. 1, e3613, jan./abr. 2021

DOI: https://doi.org/10.25053/redufor.v6i1.3613

https://revistas.uece.br/index.php/redufor/index 


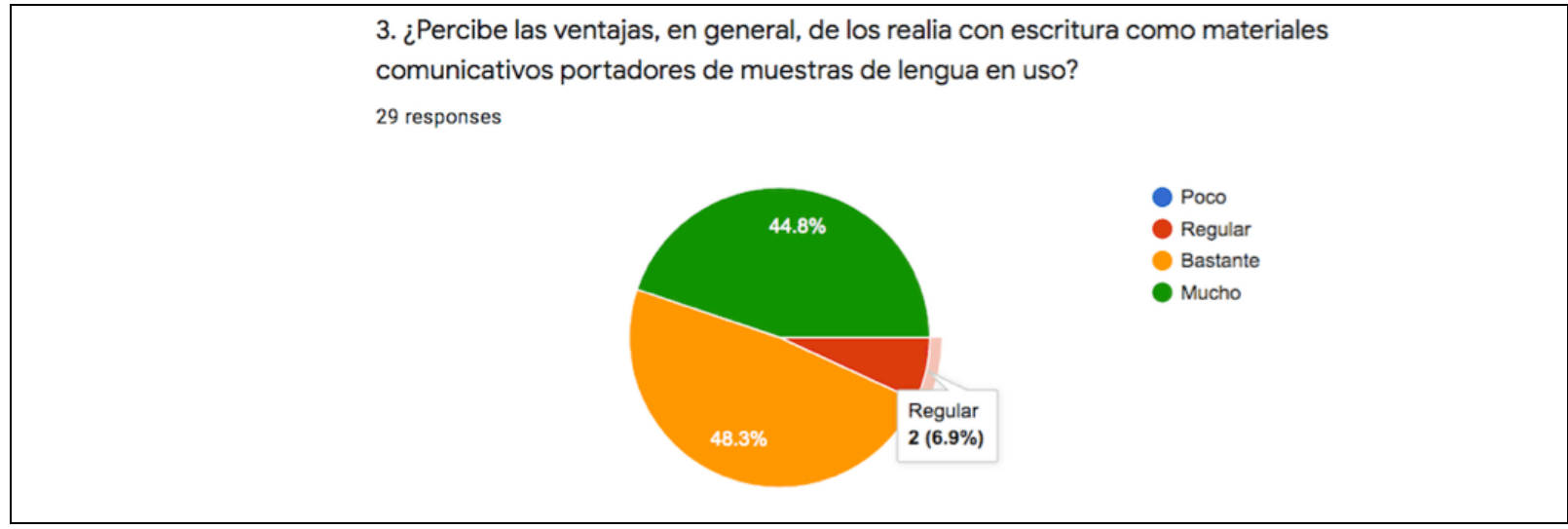

4. ¿Encuentra útil la práctica con realia con escritura para la reflexión sobre la propia lengua materna o L1 (proceso metalingüistico)?

29 responses
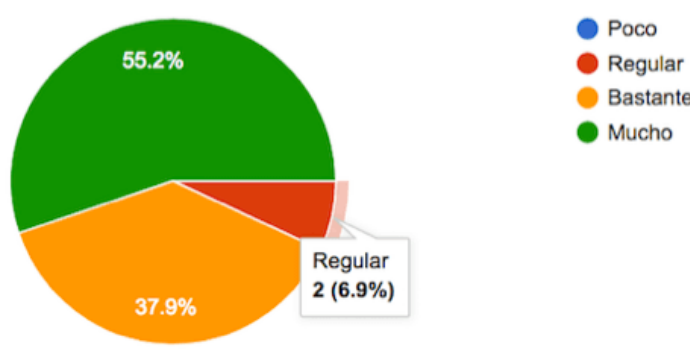

5. ¿Percibe que los realia con escritura pueden dar pie a trabajar diferentes tipos de contenidos epistemológicos de la Especialidad?

29 responses

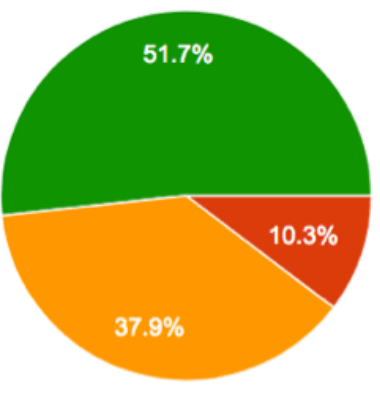

El ítem 06 propone en sus respuestas (cerradas) cinco opciones excluyentes, aunque con enunciados de respuesta más elaboradas que los cinco ítems anteriores. Se generan nuevamente 29 respuestas válidas (100\%). 
6. ¿Dónde identifica las (mayores) dificultades encontradas al aplicar el Proyecto de uso de los realia con escritura?

29 responses

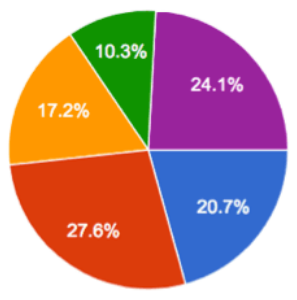

En el reconocimiento o diagnóstico de contenidos epistemológicos en los objetos recibidos

- En el diseño/creación de dinámicas con los objetos recibidos

- En la elección del perfil académico del grupo destinatario

No he encontrado dificultades

Se cierra el cuestionario con los ítems 07 y 08 . El ítem 07 da opción a una respuesta abierta (sin enunciados guiados) frente al 08 , que es de pregunta mixta (ofrece opciones guiadas y la posibilidad de añadir otras personales).

Aportamos de ambos, por su diversidad, todas las respuestas literales obtenidas.

\section{7. ¿Emplearia los realia con escritura en algún momento en sus clases? \\ 29 responses}

La respuesta es de 10 afirmaciones positivas "Sí" sin comentario añadido (34,5\%). 19 estudiantes (65,5\%) ofrecen una respuesta ampliada en los siguientes términos: 17 con confirmación/refuerzo a la respuesta afirmativa $(58,6 \%)$ y dos (en negrita) con ciertas dudas o reticencias (6,9\%). Todas consideradas válidas (29 respuestas, $100 \%)$.

(1) Estoy segura de que los utilizaría.

(2) Me encantaría poder hacerlo en mis inminentes prácticas en el centro.

(3) Por supuesto.

(4) Probablemente sí, incidiría en llevar textos tales como carteles, textos escritos de la cotidianidad (instruccciones, comunicados que pueda haber en los pasillos del propio centro en el que esté trabajando, etc.) para que entiendan la importancia de conocer ciertos elementos teóricos sobre su propia lengua.

(5) Sí, considero que es una metodología significativa.

(6) Probablemente utilizaré realias en los primeros cursos y en grupos reducidos. Me resulta interesante realias relacionados con ámbitos comunicativos de la vida diaria.

(7) Espero poder hacerlo en el futuro.

(8) Puntualmente sí, pero soy escéptico con respecto a que el alumnado demuestre interés por la gramática u otros contenidos epistemológicos en objetos cotidianos.

(9) Sí, porque permiten demostrarle al alumnado que la lengua es una herramienta presente en la vida cotidiana.

(10) Estoy segura de que los utilizaría.

Educ. Form., Fortaleza, v. 6, n. 1, e3613, jan./abr. 2021

DOI: https://doi.org/10.25053/redufor.v6i1.3613

https://revistas.uece.br/index.php/redufor/index 
(11) Sí, me parece un recurso muy interesante y que intentaré incluir en mis clases.

(12) Sí, puesto que son de fácil acceso y muy diversos para la enseñanza de la lengua o la literatura.

(13) Siempre se puede introducir de alguna forma esta técnica. Lo bueno es que se puede trabajar con casi todos los temas que se trabajan en el aula.

(14) Sí, siempre y cuando en el grupo no se encuentren alumnos con NEAE, puesto que complicaría el diseño de actividades que pudieran adaptarse a ellos.

(15) Sí, seguramente sí lo haría.

(16) Sin duda, no debemos olvidar que el lenguaje está al servicio del ser humano y le permite a este entender y construir la realidad que lo rodea. Los realia suponen un gran método para que los alumnos aprendan sobre los diversos planos de la realidad de una manera significativa e incluso lúdica.

(17) Sí, para evidenciar el uso de la lengua en el día a día de los estudiantes y que estos no vean los aspectos que se ven en clase como algo ajeno a ellos.

(18) Sí, por supuesto, son un recurso genial.

(19) Sin duda alguna.

Y finalmente, el ítem 08, que presenta una respuesta no válida (3,4\%) frente a 28 válidas $(96,6 \%)$.
8. Podria comentar para qué tipo de contenidos le parecen más aprovechables los realia con escritura. Si para (1) los conceptuales (léxico-semánticos, morfológicos...); si para los (2) nociofuncionales o instrumentales (saber hacer un resumen, etc.); si para (3) los literarios; si par (4) los socioculturales, transversales...
29 responses

(1) Jh.

(2) Para todos.

(3) Para todo tipo según el material en concreto. Son muy aprovechables.

(4) Creo que es muy útil y creativo para los literarios.

(5) Para (3) los literarios y (4) los socioculturales/transversales

(6) Considero muy útil las realias para generar la aplicación de conceptos y, a su vez, la comprensión de la lengua.

(7) 4 .

(8) Para los contenidos (1) y (4)

(9) Creo que tanto para los contenidos literarios como para los léxico-semánticos es muy interesante darle una nueva vuelta de tuerca a los objetos cotidianos y aprender a través de ellos. Utilizaremos lo cotidiano como excusa para abrir debates y tratar muchos temas dispares con nuestro alumnado.

(10) (3) los literarios, porque el componente creativo es más fácil de explotar con los objetos coditianos.

(11) Los realia con escritura me parecen más aprovechables para los contenidos socioculturales y literarios, estos últimos especialmente si los textos están relacionados con el ámbito de la publicidad.

(12) Creo que el alumnado considerará más significativo aquel aprendizaje que entiendan como funcional o sociocultural, puesto que, al final, lo que siempre están buscando es la "utilidad" de aquello que dan en las aulas, buscan poder aplicar lo que aprenden dentro en el mundo exterior, y el aula jamás debe estar desconectada de las necesidades reales de la vida cotidiana. Esto no quiere decir que no puedan darse algunos conceptos epistemológicos a través de los realia, pero sí que parece más un pretexto, al que es difícil que un alumno le vea la función, salvo que esté muy bien justificado con la intencionalidad del mensaje de aquello que se está presentando con texto. Al final, lo importante es que el alumnado sea capaz de entender el porqué se está realizando algo y para qué le sirve.

Educ. Form., Fortaleza, v. 6, n. 1, e3613, jan./abr. 2021

DOI: https://doi.org/10.25053/redufor.v6i1.3613

https://revistas.uece.br/index.php/redufor/index 
(13) Me parece muy aprovechable el uso del realia para trabajar conceptos socioculturales y transversales.

(14) Elaborando nuestro trabajo en grupo sobre REALIA, hemos podido comprobar que hay muchísimas actividades, tanto para contenidos conceptuales, gramaticales, literarios, etc., por lo que creo que trabajar la realia con escritura es útil para todos los contenidos de nuestra asignatura.

(15) Creo que son especialmente interesantes desde el punto de vista sociocultural, pero considero que también lo pueden ser para los contenidos conceptuales e instrumentales.

(16) Se pueden aprovechar, en el mismo grado de importancia, para cualquier contenido. Todo depende del tema que quieras impartir en clase.

(17) (1) que creo que es lo más complicado de enseñar y que aprendan los alumnos.

(18) Con la única excepción de los contenidos conceptuales, considero que el resto de contenidos es perfectamente compatible para poder aprovechar los realia con escritura, puesto que, después de esta experiencia, es muy difícil crear actividades que permitan trabajar contenidos lingüísticos.

(19) 1: los conceptuales.

(20) Quizá más para (1) y (4).

(21) Los conceptuales (léxico-semánticos, morfológicos...).

(22) Es evidente la gran utilidad que los realia tienen en todos los casos mencionados. No obstante, si debo destacar uno sobre el resto, considero que son especialmente atractivos para trabajar contenidos socioculturales y transversales.

(23) 1.

(24) Los realia con escritura se podrían aprovechar para abordar todos los contenidos nombrados, ya que los alumnos, a través de esos objetos escritos, aprenderían mucho y les resultaría más dinámico y motivador.

(25) Los contenidos conceptuales, los nociofuncionales o instrumentales y los socioculturales.

(26) 3 y 4 .

(27) Nociofuncionales, socioculturales y conceptuales.

(28) Depende del material que se utilice, pero principalmente socioculturales y conceptuales.

(29) Para todo tipo de contenidos.

\section{Discusión}

La observación de las distintas fases de esta investigación y la reflexión sobre sus resultados evidencian el gran interés de los participantes por las metodologías activas $y$, en general, por lo que suponga una nueva mirada a la didáctica de la especialidad de LCyL. El proyecto pretendió, desde su inicio mismo, involucrar a los participantes, profesorado en formación, seriamente comprometido con su inminente desempeño docente y ávido por desarrollar modos más eficaces de comunicar los rudimentos de los contenidos de su especialidad.

El grupo participante tuvo que organizar, una vez constituidos los subgrupos de trabajo, el desarrollo y cumplimiento de su tarea al margen de las sesiones docentes presenciales, con la excepción de las sesiones prácticas (dos horas de las ocho totales semanales) desarrolladas en el aula de Informática, donde sí podían dedicar tiempo al 
Proyecto. De hecho, un 20,7\% de los participantes (seis estudiantes) encontraron (ítem 06) las mayores dificultades en su fase organizativa con su equipo de trabajo.

El $48,3 \%$ de los participantes (14 estudiantes) valoran con la máxima categoría ("Mucho") las ventajas motivacionales de los realia con escritura (ítem 01), seguidos de 13 $(44,8 \%)$ que señalan "Bastante". Un 44,8 \% (13 estudiantes) indican con ese mismo valor máximo ("Mucho") el alineamiento de esta metodología con el aprendizaje significativo (ítem 02) y 12 (41,4 \%) eligen "Bastante". En ese mismo porcentaje positivo, 44,8 \% (13 estudiantes) perciben las ventajas de los realias con escritura como textos portadores de muestras de lengua en uso (ítem 03) y 14 señalan "Bastante" (48,3 \%). En un porcentaje mayor, 55,2 \% (16 estudiantes) encuentran útil esta metodología para activar la reflexión metalingüística en su lengua materna, calificándola así con su valor máximo (ítem 04), junto a 11 (37,9 \%) que señalan "Bastante", dando así este ítem un saldo positivo total de 27 estudiantes apostando por su fortaleza para el mejor conocimiento de la L1. También más de la mitad del grupo (51,7 \%, 15 estudiantes) identifica con el máximo valor las oportunidades de los realia con escritura para abordar los contenidos epistemológicos (ítem 05), seguido de un 37,9 \% (11 estudiantes) que señalan "Bastante". Todos afirman su predisposición a emplearlos en su futura práctica docente (ítem 07) y solo dos de ellos apostillan cierta reticencia (creen que habrá desinterés por vincularlos con la gramática; prevén dificultad con alumnado NEAE). Finalmente, el ítem 08 recoge la siguiente diversidad de opiniones: votos que indican la adecuación de los realia con escritura para abordar todos los contenidos (6 votos); para los Epistemológicos o conceptuales (12 votos); para los Nociofuncionales o instrumentales (5 votos); para los Literarios (7 votos); para los Socioculturales o transversales (14 votos).

\section{Consideraciones finales}

Este Proyecto quiere ser una invitación a la necesidad de buscar alternativas didácticas incentivadoras de la motivación docente. Especialmente advierte de la potencialidad en la aplicación de los realia con escritura en el abordaje de los contenidos socioculturales o transversales y en los epistemológicos o conceptuales de la materia de Lengua Castellana y Literatura. Reivindica, en última instancia, la práctica con toda suerte de tipologías textuales, sobre todo con las más cercanas a las necesidades 
comunicativas reales de los hablantes, conscientes de que conocer una lengua es también dominar cómo resolver el mundo con ella.

Los criterios para seleccionar el conjunto de objetos puede variar; en nuestro caso, han sido muy personales y vinculados al propio desempeño docente así como a reflexiones e investigaciones académicas previas dirigidas por nosotros (CARRASCO, 2016; CAZORLA, 2013; HERNÁNDEZ, 2017). Apostillando a Mochón (2005, p. 3), "Los realia [con escritura] rompen con la monotonía y, a veces, con el tedio que supone saber que mañana veremos la página 34 porque hoy ya hemos finalizado la 33 ".

\section{Referencias}

ÁLVAREZ, A. Objetos valiosos en la clase de ELE. Actas de las IV Jornadas Didácticas del Instituto Cervantes de Mánchester, 2011.

ALVIRA, F. La encuesta: una perspectiva general metodológica. Madrid: Cuadernos metodológicos 35 - CIS, 2011.

BAELO, M.; HAZ, F. E. Metodología de investigación en Ciencias Sociales y Jurídicas. Valencia: Tirant Humanidades, 2019.

BERWARLD, J. Teaching foreign languages with realia and other authentic materials. Washington, DC: Eric, 1987.

CANCELAS, L. P. Realia o material auténtico. ¿Términos diferentes para un mismo concepto? en Creación de materiales para la Innovación educativa con nuevas tecnologías. EDUTEC 97, p. 391-394, 1998.

CARRASCO, A. Los objetos también hablan: didáctica de materiales realia en el aula de secundaria. Las Palmas de Gran Canaria: ULPGC, 2016.

CAZORLA, L. Á. Del aula a la despensa: lectoescritura de andar por casa. Las Palmas de Gran Canaria: ULPGC, 2013.

CONSEJO DE EUROPA - MCERL. Marco común europeo de referencia para las lenguas: aprendizaje, enseñanza, evaluación. Madrid: Ministerio de Educación, Cultura y Deportes/IC/Anaya, 2002.

DECRETO 83/2016, de 4 de julio, por el que se establece el currículo de la Educación Secundaria Obligatoria y el Bachillerato en la Comunidad Autónoma de Canarias. Boletín Oficial de Canarias, 15 jul. 2016. Disponible en:

https://www.gobiernodecanarias.org/educacion/web/secundaria/informacion/ordenacioncurriculo/curriculos_eso_lomce.html. Accedido el: 20 abr. 2020. 
DEWEY, J. Cómo pensamos: la relación entre pensamiento reflexivo y proceso educativo. Barcelona: Paidós, 2007.

FERNÁNDEZ, C. Selección de manuales y materiales didácticos. Cuadernos Cervantes de la Lengua Española, Madrid, v. 27, p. 17-43, 2000.

GEBHARD, J. G. Teaching English as a foreign language: a teacher self-development and methodology guide. Ann Arbor: The University of Michigan, 1996.

GELABERT, M. J. et al. Producción de materiales para la enseñanza del español. Madrid: Arco, 2002.

HERNÁNDEZ, J. Realia: la realidad de las cosas. Investigación y actuación didáctica para las aulas de 5ํㅡ y ${ }^{\circ}$ de primaria. Las Palmas de Gran Canaria: ULPGC, 2017.

ICART, T.; PULPÓN, S. (coord.). Cómo elaborar y presentar un proyecto de investigación, una tesina y una tesis. Barcelona: Universidad de Barcelona, 2012.

IGLESIAS, J.; GALICIA, I. X. El impacto de la auto-observación en la autoeficacia del docente universitario. Revista Interuniversitaria de Formación del Profesorado, Zaragoza, v. 93 , n. 32.3 , p. 113-126, 2018.

JEWITT, C. Multimodality and literacy in school classrooms. Review of Research in Education, New York, v. 32, n. 1, p. 241-267, 2008.

JUNGES, F. C.; KETZER, C.; OLIVEIRA, V. M. Formação continuada de professores: Saberes ressignificados e práticas docentes transformadas. Educação \& Formação, Fortaleza, v. 3, n. 3, p. 88-101, 2018. DOI: https://doi.org/10.25053/redufor.v3i9.858. Disponible en: https://revistas.uece.br/index.php/redufor/article/view/858. Accedido el: 20 abr. 2020.

KRESS, G. Multimodality: a social semiotic approach to contemporary communication. London: Routledge, 2010.

KRESS, G.; VAN LEEUWEN, T. Reading images: the grammar of visual design. London: New York: Routledge, 1996.

LIMA, I. S.; ANDRADE, A.; COSTA, N. M. A práctica pedagógica en la formación inicial de docentes en Cabo Verde: perspectivas de los supervisores. Educação \& Formação, Fortaleza, v. 5, n. 1, p. 3-26, 2020. DOI: https://doi.org/10.25053/redufor.v5i13.1448. Disponible en: https://revistas.uece.br/index.php/redufor/article/view/1448. Accedido el: 20 abr. 2020.

LÓPEZ, Z. El análisis multimodal del anuncio publicitario audiovisual para el aula de Lengua Castellana y Literatura en Educación Secundaria y Bachillerato. Educação \& Formação, Fortaleza, v. 5, n. 3, e2839, 2020. DOI: 
https://doi.org/10.25053/redufor.v5i15set/dez.2839. Disponible en:

https://revistas.uece.br/index.php/redufor/article/view/2839. Accedido el: 20 oct. 2020.

MARTíN, M. C. Diseño y validación de cuestionarios. Matronas Profesión, Madrid, v. 5, n. 17, p. 23-29, 2004.

MERRILL, M. D. First principles of instruction. Educational Technology Research and Development, v. 50, n. 3, p. 43-59, 2002. DOI: https://doi.org/10.1007/BF02505024. Disponible en: https://mdavidmerrill.wordpress.com/publications/first-principles-ofinstruction/. Accedido el: 20 abr. 2020.

MOCHÓN, A. Los materiales reales en la formación y docencia del profesorado para la enseñanza de la lengua y cultura española. In: FIAPE, 1., 2005, Toledo. Anales...

Toledo: Fiape, 2005.

MURILLO, F. J.; MARTÍNEZ-GARRIDO, C.; HERNÁNDEZ-CASTILLA, R. Decálogo para una enseñana eficaz, Reice, Madrid, v. 9, n. 1, p. 6-27, 2011.

PASTOR, S. El papel de la reflexión metalingüística en la adquisición de la gramática de E/LE. In: CONGRESO INTERNACIONAL DE ASELE, 15., 2004, Sevilla. Actas... Sevilla, Asele, 2004.

PERALES, J. La conciencia metalingüística y el aprendizaje de una L2/LE. In: SÁNCHEZ LOBATO, J.; SANTOS GARGALLO, I. (dir.). Vademécum para la formación de profesores: enseñar español como segunda lengua (L2)/Lengua extranjera (LE). Madrid: SGEL, 2004. p. 329-349.

RICHARDS, J.; PLATT, J.; PLATT, H. Longman Dictionary of Language Teaching \& Applied Linguistics. Essex: Longman, 1992.

RYAN, R. M.; DECl, E. L. Intrinsic and extrinsic motivations: classic definitions and new directions. Contemporary Educational Psychology, v. 25, p. 54-67, 2000.

SCHANK, R. Lessons in Learning, e-Learning, and Training: perspectives and guidance for the enlightened trainer. Santiago: Pfeiffer, 2005.

VALLÉS, M. S. Técnicas cualitativas de investigación social: reflexión metodológica y práctica profesional. Madrid: Síntesis, 1999. 


\section{Anexo 1 - Proyecto de cierre, investigación}

ULPGC - FCEDU 2019-2020

Máster universitario en Formación del Profesorado de Educación Secundaria obligatoria y Bachillerato, Formación Profesional y Enseñanza de Idiomas por las Universidades de La Laguna y Las Palmas de Gran Canaria Aprendizaje y Enseñanza de la Lengua castellana y la Literatura (Dimensión lingüística) http://solotuaprendizaje.blogspot.com

\section{Proyecto de cierre La lengua de las cosas: leer los objetos. Uso de los Realia con escritura}

Con este Proyecto, planteado como cierre de la materia, se pretende una reflexión y al tiempo una investigación (en grupos cooperativos) sobre el aprovechamiento de los Realia con escritura en el ámbito académico. Persigue evidenciar la fortaleza pedagógica de los objetos cotidianos, domésticos que contengan escritura y que permitan una aproximación, desde la perspectiva conjunta motivacional y epistemológica, a contenidos de la especialidad.

Encierra una fase (a) de selección de materiales, a partir de una oferta proporcionada por la profesora para determinar, acto seguido, los potenciales contenidos útiles para el aula. A continuación se diseñará (y presentará oralmente) su explotación didáctica con una breve ficha o itinerario que muestre el aprovechamiento de los objetos seleccionados.

La clave está en delimitar la variedad de contenidos susceptibles de encontrarse en los objetos. Así: a) contenidos epistemológicos de la especialidad (conceptuales lingüísticos: fonético-fonológicos, léxicosemánticos, morfológicos, gramaticales) y literarios.

b) contenidos nociofuncionales ("saberes instrumentales").

c) contenidos socioculturales (transversales, estilísticos...).

Se pensará en un hipotético contexto (grupo destinatario, breve contexto académico, objetivos) de aplicación para valorar la adecuación de las actividades a ese nivel/marco elegido.

Metodológicamente hablando partimos del enfoque del aprendizaje significativo que busca atender tanto la variable motivacional (aprender a partir de lo que ya sabemos, involucrarnos, interés, autoeficacia y meta competencial) como la propia reflexión metalingüística sobre la L1, básica en la inmediata praxis de los masterandos.

\section{Resumiendo:}

-Cada equipo de trabajo se lleva su "compra". Reparto, reflexión individual y puesta en común. -Diagnóstico: ¿para qué contenidos podrían ser adecuados los objetos de mi compra?

-Elección de un brevísimo perfil de aula (nivel, grupo, algunas características...).

-Acomodo de hasta tres objetivos específicos o concretos.

-Descripción de varias actividades/dinámicas que justifiquen el aprovechamiento didáctico de la "compra".

Se valorará la integración de contenidos, la perspectiva interdisciplinar y transversal y el sentido motivacional, lúdico y creativo.

Bibliografía de referencia (TFT dirigidos)

Hernández Guedes, J. (2017). Realia: la realidad de las cosas. Investigación y actuación didáctica para las aulas de $5^{\circ}$ y $6^{\circ}$ de primaria. Las Palmas de Gran Canaria: Repositorio ULPGC

Carrasco Nogales, A. (2016). Los objetos también hablan: didáctica de materiales realia en el aula de secundaria. Las Palmas de Gran Canaria: Repositorio ULPGC.

Cazorla Monzón, Leticia de los Ángeles. (2013). Del aula a la despensa: lectoescritura de andar por casa.

Lectura motivadora sobre la estética de los objetos, el diseño y el "consuelo" del lujo, las marcas, etc.

Sudjic, D. (2009). El lenguaje de las cosas. Madrid: Turner.

Educ. Form., Fortaleza, v. 6, n. 1, e3613, jan./abr. 2021

DOI: https://doi.org/10.25053/redufor.v6i1.3613

https://revistas.uece.br/index.php/redufor/index 
Anexo 2 - Rúbrica, ejercicio escrito de coevaluación

\section{ULPGC - FCEDU - MUFP \\ EXPOPROYECTO DE CIERRE \\ La lengua de las cosas: leer los objetos. \\ Uso de los Realia con escritura}

Ficha de Co-evaluación/valoración (cualitativa) de las propuestas presentadas

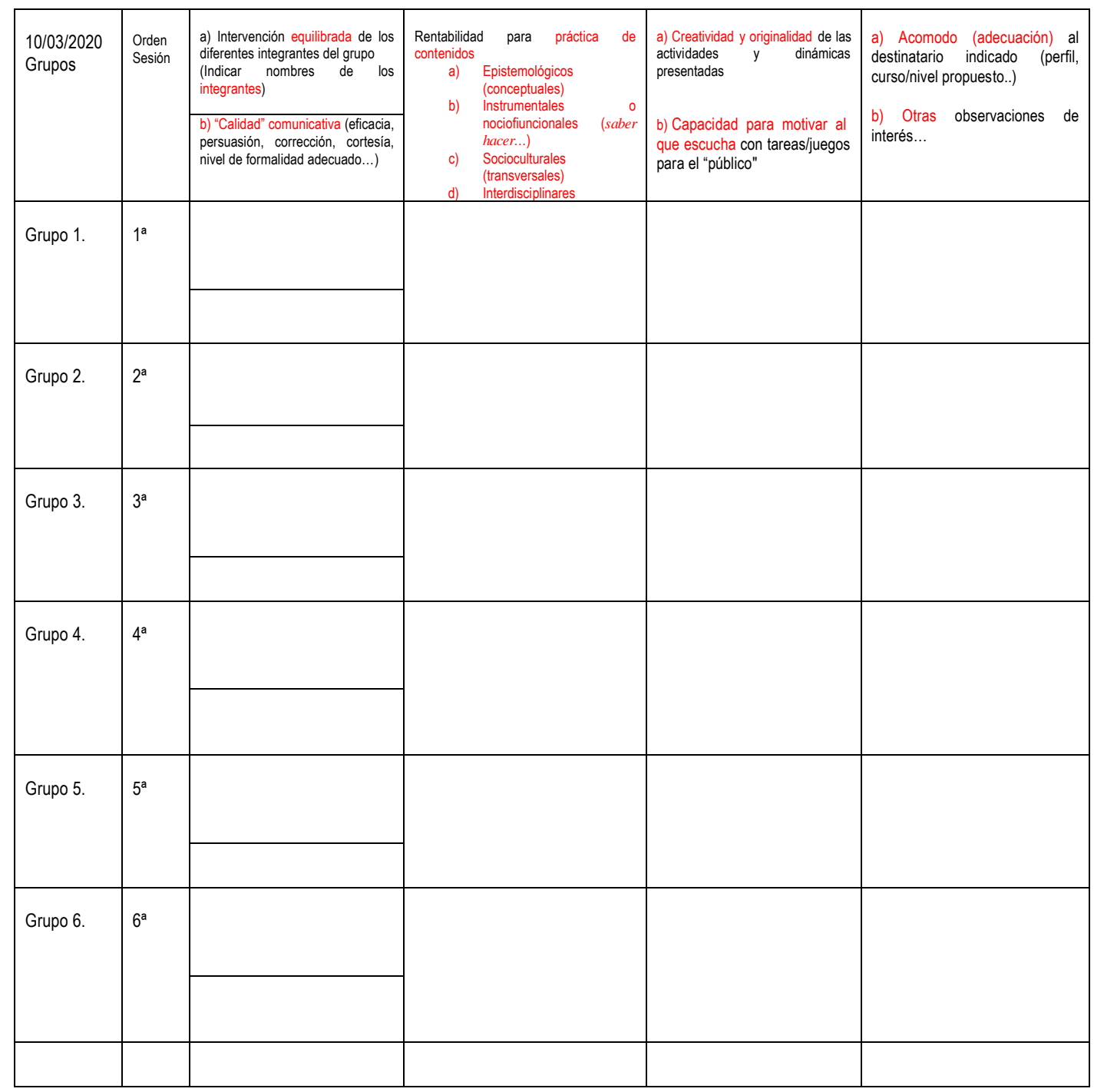

Educ. Form., Fortaleza, v. 6, n. 1, e3613, jan./abr. 2021

DOI: https://doi.org/10.25053/redufor.v6i1.3613 
Anexo 3 - Ejemplos de diseños de los participantes

\section{Cartones de yogures Light\&Free}

Creación y disefio por grupos de un nuevo cartón pensado para yogures que sí tengan azúcar, edulcorantes u otros añadidos artificiales haciendo uso de versos, figuras o rasgos de la poesia modernista, lo que va conlleva una pequeria labor investigadora y la comprension de este tipo de literatura.
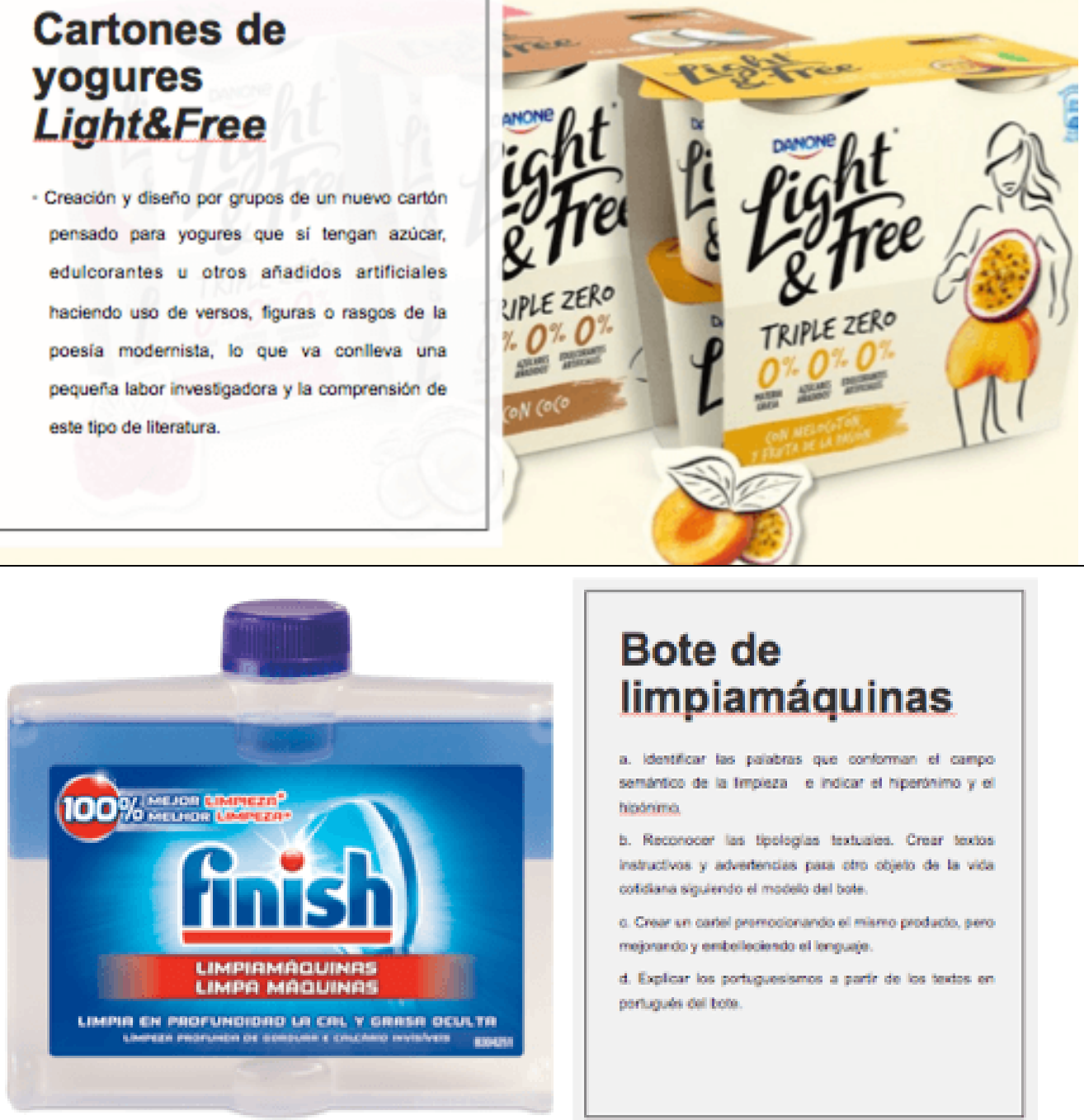

\section{Bote de} limpiamáquinas

2. identicar los paratras que contoman ef cange senumber de la impieza e ndicar st hiperbaimo $y$ e. hoshima

b. Reconocer las tipsisgias texthaies. Crear sexsos

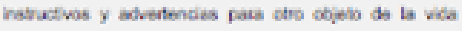
cotisana sogiendo ed mocello del bote

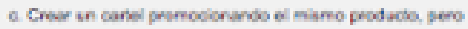
mojpardo y enteleciondo el ienguaje

d. Explear los potuguesimos a parte de los vedise en pangude cel tow.

\section{Caja de zapatos}

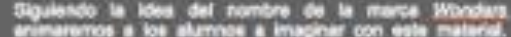

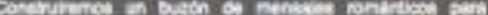

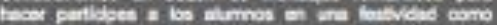
puedurer Ear vatosth

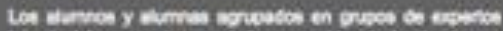

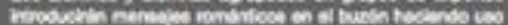

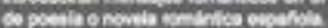




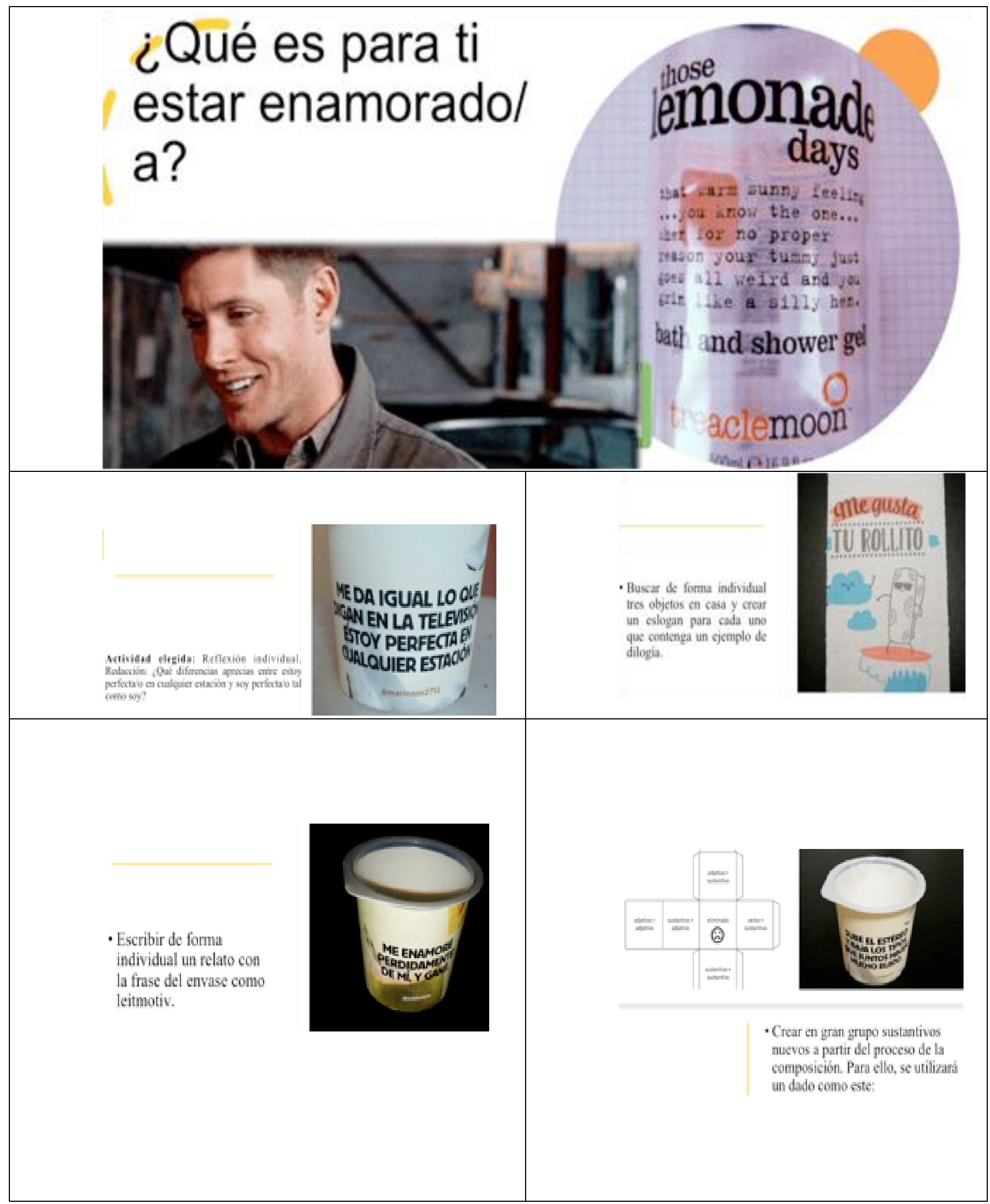

Educ. Form., Fortaleza, v. 6, n. 1, e3613, jan./abr. 2021

DOI: https://doi.org/10.25053/redufor.v6i1.3613

https://revistas.uece.br/index.php/redufor/index 


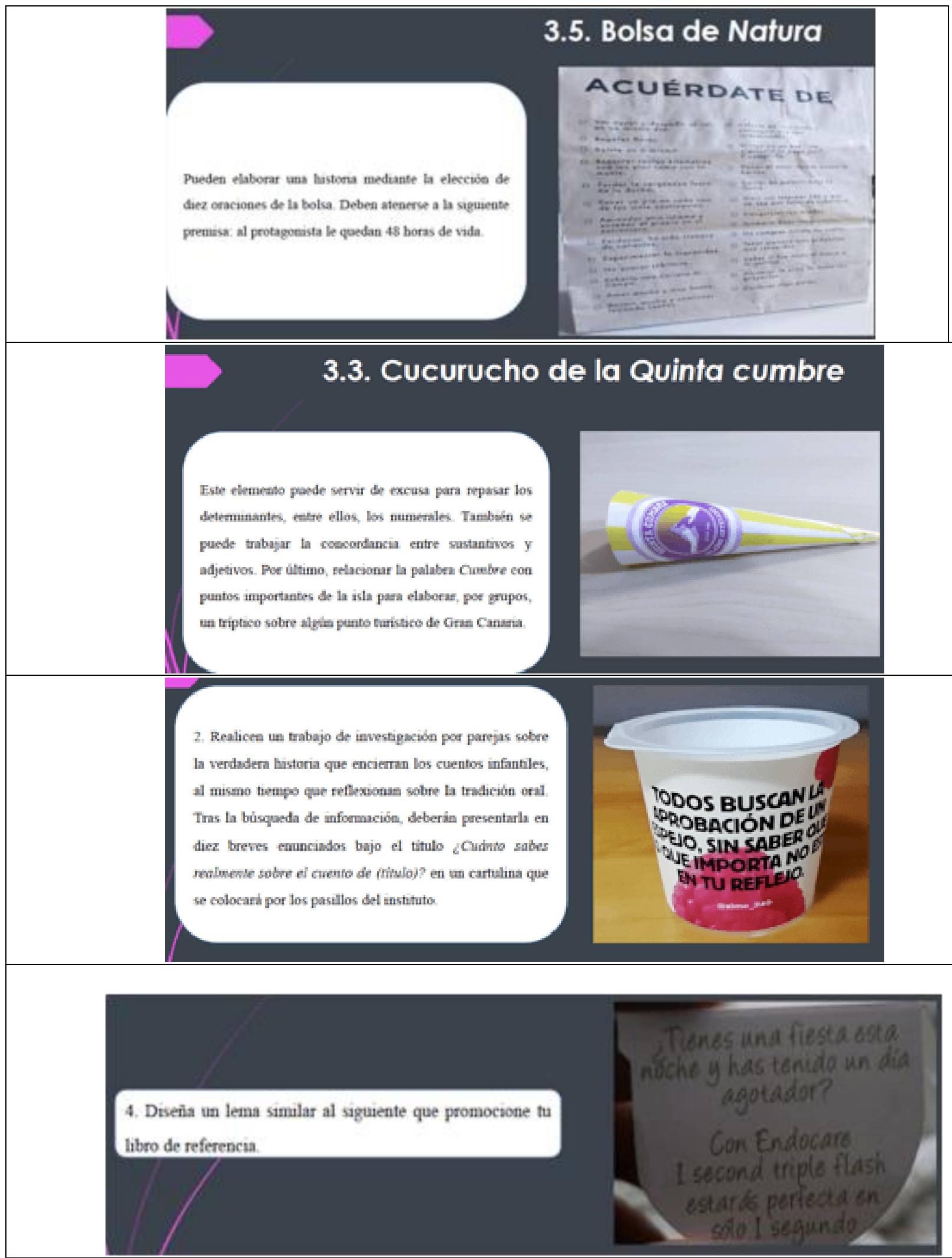

Educ. Form., Fortaleza, v. 6, n. 1, e3613, jan./abr. 2021

DOI: https://doi.org/10.25053/redufor.v6i1.3613

https://revistas.uece.br/index.php/redufor/index 


\section{Servilletas de Paris:}

Los alumnos deberán diseñar sus propias servilletas, incluyendo una frase o palabra típica del dialecto canario y añadir dibujos relacionados.

Esta actividad podemos realizarla junto a la asignatura de plástica.

Contenidos: socioculturales e interdisciplinares.

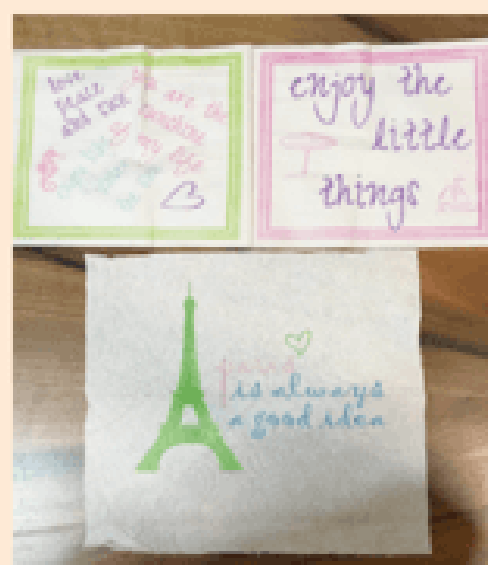

\section{Bolsa con mapa:}

Después de que los alumnos pongan en común qué tipos de novela conocen, dividiremos la clase en parejas con el fin de inventar el mapa de una pequeña población. Tendrán que añadir los principales edificios de una ciudad y podrán inspirarse en una tipologia de novela concreta para inventar el nombre de sus calles. Cuando terminen, jugarán a adivinar en qué lugar del mapa se encuentra el compañero, siguiendo sus indicaciones de manera oral.

Contenidos: nociofuncionales y socioculturales.

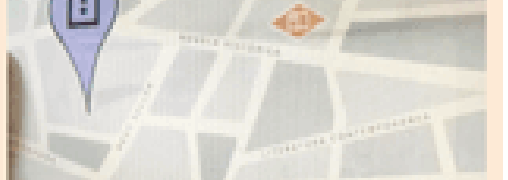

UN DESTINO GOMÚN

\section{Caiita oso:}

Los alumnos, por pequeños grupos, deberán escribir un microrrelato, partiendo de la imagen que se muestra en la caja.

En algún momento de la historia deberán incluir la palabra "celestial" que aparece en la imagen.

Contenidos : epistemológicos.

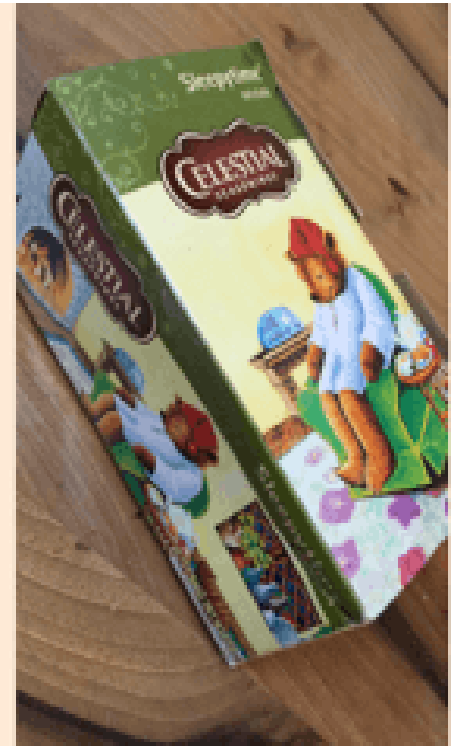

Educ. Form., Fortaleza, v. 6, n. 1, e3613, jan./abr. 2021

DOI: https://doi.org/10.25053/redufor.v6i1.3613

https://revistas.uece.br/index.php/redufor/index 
Juana-Rosa Suárez Robaina, Universidad de Las Palmas de Gran Canaria, Departamento de Didácticas Específicas

i(Dhttps://orcid.org/0000-0002-5391-7344

Doctora en Filología Española por la Universidad de Las Palmas de Gran Canaria (ULPGC) con licenciatura previa en Filología Hispánica por la Universidad Nacional de Educación a Distancia (UNED). Titular (en excedencia voluntaria) de Enseñanza Secundaria (Especialidad de Lengua Castellana y Literatura). Docente e investigadora en la Facultad de Ciencias de la Educación (FCEDU), en la que ostenta el cargo de vicedecana de Cultura e Igualdad. Pertenece al Departamento de Didácticas Específicas de la ULPGC. Con formación especializada en la Didáctica del Español para extranjeros (2 Másteres) y experto universitario en Docencia universitaria. Premio de investigación Viera y Clavijo (2000, Letras, Sección Literatura).

Contribución de autoría: Escrita e revisión del artículo.

E-mail: juanarosa.suarez@ulpgc.es

Editora responsable: Lia Machado Fiuza Fialho Pareceristas ad hoc: Zósimo Pena y Daniel Escándela Montiel

\section{Cómo citar este artículo (ABNT):}

SUÁREZ ROBAINA, Juana-Rosa. Realia con escritura: motivación y reflexión metalingüística sobre la L1 en la formación del profesorado. Educ. Form., Fortaleza, v. 6, n. 1, e3613, 2020. Disponible en: https://revistas.uece.br/index.php/redufor/article/view/3613

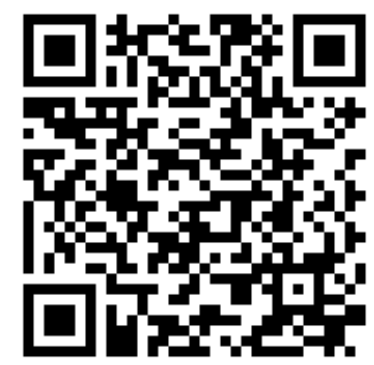

Recibido el 21 de julio de 2020.

Aceptado el 9 de agosto de 2020.

Publicado el 10 de noviembre de 2020.

Educ. Form., Fortaleza, v. 6, n. 1, e3613, jan./abr. 2021

DOI: https://doi.org/10.25053/redufor.v6i1.3613

https://revistas.uece.br/index.php/redufor/index 